$5^{\text {th }}$ US Combustion Meeting

Organized by the Western States Section of the Combustion Institute and Hosted by the University of California at San Diego

March 25-28, 2007.

\title{
Radiative Extinction of Gaseous Spherical Diffusion Flames in Microgravity
}

\author{
K. J. Santa ${ }^{1}$, B. H. Chao ${ }^{1}$, P. B. Sunderland ${ }^{2}$, D. L. Urban ${ }^{3}$, \\ D. P. Stocker ${ }^{3}$ and R. L. Axelbaum ${ }^{4}$ \\ ${ }^{1}$ Department of Mechanical Engineering, University of Hawaii at Manoa, \\ Honolulu, Hawaii 96822, USA \\ ${ }^{2}$ Department of Fire Protection Engineering, University of Maryland, \\ College park, Maryland 20742, USA \\ ${ }^{3}$ NASA Glenn Research Center, Cleveland, Ohio 44135, USA \\ ${ }^{4}$ Department of Mechanical and Aerospace Engineering, Washington University, \\ St. Louis, Missouri 63130, USA
}

\begin{abstract}
Radiative extinction of spherical diffusion flames was investigated experimentally and numerically. The experiments involved microgravity spherical diffusion flames burning ethylene and propane at 0.98 bar. Both normal (fuel flowing into oxidizer) and inverse (oxidizer flowing into fuel) flames were studied, with nitrogen supplied to either the fuel or the oxygen. Flame conditions were chosen to ensure that the flames extinguished within the $2.2 \mathrm{~s}$ of available test time; thus extinction occurred during unsteady flame conditions. Diagnostics included color video and thin-filament pyrometry. The computations, which simulated flow from a porous sphere into a quiescent environment, included detailed chemistry, transport and radiation, and yielded transient results. Radiative extinction was observed experimentally and simulated numerically. Extinction time, peak temperature, and radiative loss fraction were found to be independent of flow rate except at very low flow rates. Radiative heat loss was dominated by the combustion products downstream of the flame and was found to scale with flame surface area, not volume. For large transient flames the heat release rate also scaled with surface area and thus the radiative loss fraction was largely independent of flow rate. Peak temperatures at extinction onset were about $1100 \mathrm{~K}$, which is significantly lower than for kinetic extinction. One observation of this work is that while radiative heat losses can drive transient extinction, this is not because radiative losses are increasing with time (flame size) but rather because the heat release rate is falling off as the temperature drops.
\end{abstract}

\section{Introduction}

Diffusion flame extinction is of both fundamental and practical interest. Extinction is important to applications such as fire safety, quenching near solid boundaries, and flame anchoring in burners. Flame extinction can be characterized as either kinetic (i.e., diffusive) or radiative. Kinetic extinction occurs at short residence times (i.e., at high strain rates or scalar dissipation rates) whereas radiative extinction is expected at long residence times. Kinetic extinction can be readily observed experimentally, such as in counterflow flames when strain rate is increased to the point of extinction, and this has been extensively studied [1-3]. On the other hand, radiative 
extinction, which was theoretically predicted by Chao et al. [4] for droplet burning, is much more difficult to observe, and researchers have been seeking compelling experimental evidence for this phenomena. Radiative extinction occurs at very low strain rates and for this reason it is of particular interest for spacecraft fire safety, where buoyancy is not available to accelerate (strain) the flow field.

Radiative extinction of spherical diffusion flames, whether droplet or burner supported, is predicted by a simple scaling analysis. Radiative loss rate scales with flame surface area (i.e., the square of the flame radius) times the thickness of the high-temperature zone. This thickness is independent of flame radius in the limit of large flames (although it increases with flame radius for small flames) [4]. Thus, for large flames, radiation scales with radius squared (for small flames it scales with radius raised to a power of between $2-3$ ). On the other hand, both the heat release rate and the flame radius of quasi-steady flames are proportional to the reactant flowrate $[5,6]$. Thus, in large quasi-steady flames, the radiative heat loss fraction scales with flame radius (for small flames it scales with radius raised to a power of between 1-2). For radiative extinction to occur the rate of radiative heat loss must be comparable to the rate of heat release and since for large microgravity flames this ratio scales with radius, radiative extinction can occur for these flames.

Radiative extinction is unlikely in normal gravity because buoyancy increases with flame size, and under conditions where radiative extinction might otherwise occur buoyancy enhances mixing and reduces residence times. On the other hand, radiative extinction can be important in microgravity and an improved understanding of this phenomenon could contribute to spacecraft fire safety. Microgravity experiments allowed the first observation of radiative extinction, this being for droplet combustion [7,8]. Extinction occurred for quasi-steady burning of large droplets, for which flame radius is proportional to droplet radius and the above scaling predicts large radiative loss fractions.

Radiative extinction also is possible in burner-supported spherical diffusion flames. For quasisteady burning, flame radius is proportional to reactant flowrate [6,9]. As the above scaling indicates, at high enough reactant flowrates radiative extinction should occur. Radiative extinction was observed in microbuoyant burner-supported spherical flames in normal gravity by Yoo et al. [10], but these were not truly nonbuoyant flames and a small amount of buoyancy can have a significant impact on flames near extinction. Theoretical work on spherical flames was presented in King [11], Atreya and Agrawal [12], Mills and Matalon [6,13], Christiansen et al. [14] and Liu et al. [9]. Radiative extinction has also been reported for counterflow flames in microgravity [15].

The time required to obtain steady-state spherical flames is typically on the order of tens of seconds. This precludes the observation of quasi-steady extinction in ground-based facilities. On the other hand, transient extinction can be observed. The experiments described here seek to understand radiative extinction in transient spherical diffusion flames. Unlike droplet burning the flow fields in these flames are steady and the unsteadiness is primarily a consequence of the evolving thermal and concentration fields. In addition, since gaseous fuels are used, the stoichiometric mixture fraction can be easily varied by varying the fuel concentration. 


\section{Experimental}

The experiments were conducted in microgravity in the NASA Glenn $2.2 \mathrm{~s}$ drop tower. The experimental apparatus is described in detail in Sunderland et al. [16,17]. The burner reactant flows from a storage tank through a solenoid valve, a metering valve, a mass flowmeter, and a second solenoid valve into the spherical burner. As before, the burner is a $6.4 \mathrm{~mm}$ diameter porous stainless-steel sphere. All tests were conducted in a pressure vessel of 26 liters initially at room temperature and 0.98 bar (with an estimated uncertainty of \pm 0.005 bar). Flames were ignited immediately after drop initiation by a hot wire.

The present tests involved either ethylene (99.9\% purity) or propane ( $99.9 \%$ purity) as fuel, as well as oxygen ( $99.999 \%$ purity) and nitrogen (99.999\% purity). Gas mixtures were prepared by partial-pressure mixing. The estimated composition uncertainty of the mixtures was \pm 0.001 mole fraction. Both normal and inverse flames were considered here. In normal flames the pressure vessel contained an atmosphere of oxidizer while in inverse flames the atmosphere contained fuel $[16,17]$. Various levels of nitrogen dilution were considered to obtain conditions where flames would ignite and then extinguish within the $2.2 \mathrm{~s}$ of available microgravity time.

The flow rate for the burner-side reactant was established in steady state in normal gravity about 30 minutes before drop initiation. The pressure drop across the porous burner, and a nonzero plumbing volume between the second solenoid valve and the burner, caused unsteady burner flowrates after flow commenced. To minimize these transients, a pressure transducer was installed just upstream of the burner, its output was recorded at $170 \mathrm{~Hz}$ during each test, and care was taken to maintain a nearly constant pressure at this location. This was accomplished by opening the first solenoid valve for a predetermined interval $(0.25-4 \mathrm{~s}$, optimized for each test condition) about $20 \mathrm{~s}$ prior to drop initiation to pressurize the plumbing system between the solenoid valves. At $1 \mathrm{~s}$ before drop initiation, both solenoid valves were opened to commence flow. During burn tests, the transducer indicated pressure drops across the burner of $0.03-1.86$ bar, corresponding to the lowest and highest steady-state flowrates considered here. This pressure drop was held constant within 10\% during each test. Thus uncertainties in the flowrates are estimated at $\pm 15 \%$.

The flames were imaged using a color charge-coupled device (CCD) video camera with 8 and 16 $\mathrm{mm}$ manual-iris lenses at $\mathrm{f} 1.4$. Spatial resolution was 0.2 and $0.1 \mathrm{~mm}$, respectively. Flame diameters were measured using the contours of peak blue emission in the video record. Diameters were determined by averaging the longest chord through each flame and its perpendicular chord.

Two modes of extinction onset were observed: base and hole extinction. Base extinction, typically observed at small flowrates, started at the base of the flame near the burner supply tube. Hole extinction, typically observed at high flowrates, started as a flame hole in the blue flame sheet at a distance away from the burner tube. Such holes grew with time. Base or hole extinction often led to complete extinction, where all flame luminosity disappeared during a drop test. For flames in which base extinction was observed, extinction time is reported as the time when $50 \%$ of the previously visible flame surface (as viewed by the video camera) was no longer visible. For flames in which hole extinction was observed, extinction time is reported as the time when a hole was first visible. Extinction times reported here are referenced to the time datum at ignition. For some tests a resistively heated wire was placed near the closest approach of the flame to the burner tube and was energized (in microgravity) to help prevent base extinction. 
Approximate peak temperatures were measured using thin-filament pyrometry, a technique pioneered by Villimpoc and Goss [18]. Four SiC fibers, with diameters of $15 \mu \mathrm{m}$, were strung across the flames in the focal plane of a Nikon D100 digital single-lens reflex camera. This color camera has $3008 \times 2000$ pixels, 12 bits per color plane, and is similar to the still cameras used previously for soot pyrometry [19] and thin-filament pyrometry [20]. The tests were conducted with a $60 \mathrm{~mm}$ lens at an f-number of 4, a shutter time of $33 \mathrm{~ms}$, a detector sensitivity of ISO 800 , a white balance of direct sunlight, and with all automatic gain and focusing disabled. A solenoid triggered the shutter release, whereby the camera recorded images at its fastest rate, allowing four images per drop test. There was no saturation in the images in any color plane. The images were converted to greyscale (with a range of $0-4095$ ) and then smoothed using $5 \times 5$ pixel binning. The brightest pixel greyscale was then recorded along each of the eight fiber-flame crossings and these were averaged and reported here.

\section{Numerical}

For the numerical simulation a gaseous reactant is injected from the porous spherical burner at a temperature $T_{b}$ into a nearly infinite quiescent environment of the other reactant at temperature $T_{\infty}$. The burner is assumed to be perfectly symmetric so that the flow field and flame are spherically symmetric in microgravity. The numerical code is a modification of the PREMIX [21] code, adapted to a diffusion flame in a spherical geometry and allowing for optically thick radiative heat losses. For this problem, the equations describing the conservation of mass, energy and gas species are:

$$
\begin{gathered}
\frac{\partial \rho}{\partial t}+\frac{1}{r^{2}} \frac{\partial\left(r^{2} \rho u\right)}{\partial r}=0 \\
\rho c_{p} \frac{\partial T}{\partial t}=\frac{1}{r^{2}} \frac{\partial}{\partial r}\left(r^{2} \lambda \frac{\partial T}{\partial r}\right)-\rho u c_{p} \frac{\partial T}{\partial r}-\sum_{k=1}^{K}\left(\rho c_{p, k} Y_{k} V_{k} \frac{\partial T}{\partial r}+h_{k} \omega_{k} Y_{k}\right)-R a \\
\rho \frac{\partial Y_{k}}{\partial t}=-\frac{1}{r^{2}} \frac{\partial}{\partial r}\left(r^{2} \rho Y_{k} V_{k}\right)-\rho u \frac{\partial Y_{k}}{\partial r}+W_{k} \omega_{k} Y_{k}, k=1,2, \cdots, K
\end{gathered}
$$

where $T$ is the temperature, $Y_{k}$ is the mass fraction of species $k, W_{k}$ is the molecular weight of species $k, t$ is time, $r$ is the radial spatial coordinate, $u$ is the radial flow velocity, $\rho$ is the gas density, $c_{p}$ is the averaged specific heat at constant pressure, $\lambda$ is the heat conductivity, $h_{k}$ is the specific enthalpy of species $k, c_{p, k}$ is the specific heat of species $k, V_{k}$ is the diffusion velocity of species $k, \omega_{k}$ is the production rate of species $k, K$ is the number of species, and $R a$ is the rate of radiative heat loss. The equations were solved subject to the following boundary conditions:

$$
\begin{gathered}
r=r_{b}: T=T_{b} ; Y_{k}\left(u+V_{k}\right)=u Y_{k, 0}, k=1,2, \cdots, K \\
r \rightarrow \infty: T \rightarrow T_{\infty} ; Y_{k} \rightarrow Y_{k, \infty}, k=1,2, \cdots, K
\end{gathered}
$$

where the subscripts $0, b$ and $\infty$ refer to conditions at the center of the burner, the burner surface and the ambient, respectively. Burner surface temperature $T_{b}$ was taken to be constant, since thermocouple measurements of the burner surface in the $2.2 \mathrm{~s}$ drop facility showed no significant increase in temperature for the flames considered. In addition, the results indicate that after $5 \mathrm{~s}$ the thermal field had only reached a radius of $9 \mathrm{~cm}$ from the center of the burner and the 
computations predicted no significant change in reactant compositions at a radius of $100 \mathrm{~cm}$. Thus, although a finite domain $\left(r_{\text {wall }}=100 \mathrm{~cm}\right)$ was used in the computations, it was effectively infinite and the results were not affected by an increase in domain size. Both $T_{b}$ and $T_{\infty}$ were taken to be $300 \mathrm{~K}$ in this study.

Radiation was considered to be optically thick and caused only by the participation of $\mathrm{CO}_{2}, \mathrm{H}_{2} \mathrm{O}$ and $\mathrm{CO}$. The radiative properties of these gases were formulated by a statistical narrow-band model with a spectral bandwidth of $25 \mathrm{~cm}^{-1}$. The emissivities were extracted from the line-byline values given by the HITRAN database [22]. To account for the angular variation of the radiation intensity, the discrete ordinates method was employed, with a discrete representation that included 20 different directions. The rate of radiative heat transfer was then evaluated by integrating over all directions using Gaussian quadrature. A more detailed description of the radiation model can be found in Carlson and Lathrop [23].

Conventional finite difference techniques with non-uniform mesh spacing were adopted for the discretization of the differential equations. The transient terms were expressed by a forward difference formula, the diffusive terms by a central difference formula, and, for better convergence, the convective terms by an upwind difference formula. The discretized equations were solved by Sandia's Twopnt package [24], which uses Newton's method to solve transient and steady-state boundary value problems. The chemical reaction rates, the thermodynamic properties, and the transport properties were evaluated by Chemkin and Transport software $[25,26]$. The kinetics data were provided by GRI-Mech 3.0, which contains 53 species and 325 reactions [27]. The number of grids was varied until the solution did not change with further addition of grids. The time step was adjusted until the solution converged.

\section{Results ans Discussion}

Figure 1 illustrates a sequence of images during a drop wherein hole extinction is seen to occur. Ignition occurs approximately $30 \mathrm{~ms}$ after the release of the rig and the onset of microgravity. The flame is evident as a faint line surrounding the porous sphere. Soot produced during the early stages is trapped thermophoretically within the flame and can be seen as the yellow luminous region around the porous sphere. The glow of the heating wire is visible at the bottom. For this flame propane is flowing into an atmosphere of $17 \%$ oxygen. After about $1.5 \mathrm{~s}$, a hole is observed in the outer flame zone between 10 and 12 o'clock. The blue flame is not visible at this location, indicating hole extinction. Soon thereafter the flame extinguishes completely and only luminous emission from residual soot is visible.

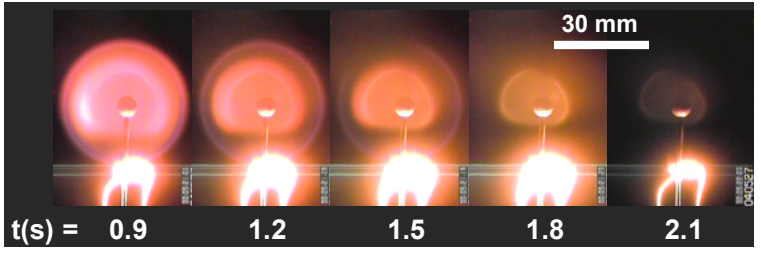

Figure 1. Time sequence of color images of an extinguishing flame of propane flowing into $17 \%$ oxygen at $1.35 \mathrm{mg} / \mathrm{s}$. The round blue region is the flame sheet, the kidney-shaped yellow region is soot, and the white region is a heating wire. The spherical burner and supply tube also are visible here. The heating wire encircles the supply tube to minimize heat loss to the tube. Hole extinction occurred at $1.47 \mathrm{~s}$.

Figure 2 illustrates base extinction for propane flowing into air with and without the heating wire. Given the apparent shape of these flames, it can be assumed that the flow field is uniform. Extinction occurs near the burner supply tube at about $1.4 \mathrm{~s}$ for both cases, indicating that the 
time to extinction is not significantly influenced by heat loss to the burner supply tube. It might be expected that instability at the "bottom" of the flame would trigger extinction of the entire flame, but this is not the case. The edge flame and unburned region at the supply tube apparently do not influence the bulk of the flame. For this reason it was assumed that base extinction is an appropriate indicator of extinction, within the experimental uncertainties, and thus most tests were performed without the heating wire.

As these drop tower experiments are intrinsically transitory, a transient numerical scheme was used to study the flames. Before comparing the numerical and experimental results we will

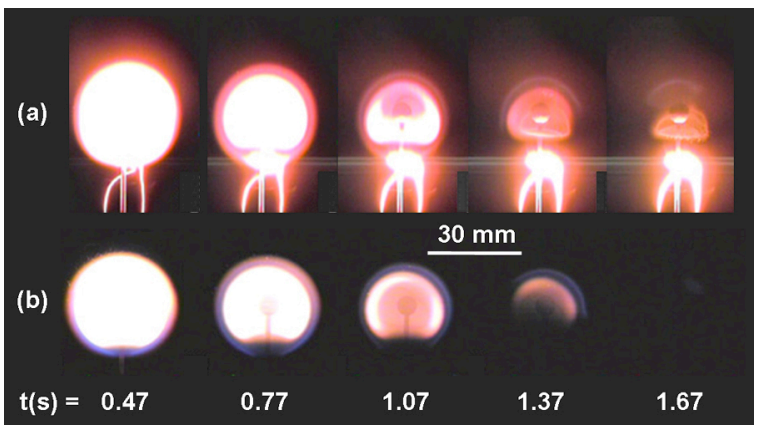

Figure 2. Time sequences of color images of extinguishing flames of propane flowing into air at $0.75 \mathrm{mg} / \mathrm{s}$, (a) with heating wire, and (b) without heating wire. The visible features are similar to those described in the caption of Fig. 1. Extinction occurred at the base (base extinction) at $1.37 \mathrm{~s}$ and $1.33 \mathrm{~s}$, respectively.

discuss the numerical simulations. There are two important considerations with respect to accuracy: convergence, which is dependent on grid spacing, and the initial condition. The former was addressed in this study by varying the grid spacing and domain size to ensure that the results were not dependent on them. The latter is more complicated because it is impossible to know what the true initial conditions are. Experimentally the flow through the porous sphere begins about $2 \mathrm{~s}$ before ignition. Under these conditions one would expect that there is a temporary premixed flame that quickly transitions to a diffusion flame. The critical feature of this ignition is an almost instantaneous establishment of a diffusion flame at some distance from the burner. This fledgling diffusion flame would yield steep gradients on either side of the flame. To simulate this ignition process we have followed the approach of Tse et al. [28] to obtain our initial condition. In this approach the initial condition is given by the compressed steady-state solution of the same flame, which is obtained by forcing the outer boundary closer to the porous sphere. In this way we produce a thin flame with a composition that is similar to what would be expected for the actual flame. In addition, since the flame is very thin immediately after ignition, radiative losses are negligible and so radiation is turned off to obtain the steady-state compressed solution. This solution is then used as the ignition source.

Figure 3 shows temperature profiles for two different initial conditions at different levels of compression, with the outer boundary at $5 \mathrm{~cm}$ (Case 1) and $3.5 \mathrm{~cm}$ (Case 2) from the center of the burner, for oxygen issuing into $4 \%$ ethylene at $104 \mathrm{mg} / \mathrm{s}$. Figure 4 illustrates the evolution of the peak temperature and flame radius for the two different initial conditions of Fig. 3. The general characteristics of the flame history include an initial increase in temperature for less than $0.1 \mathrm{~s}$, followed by a gradual reduction in temperature until extinction, which occurs at $1.50 \mathrm{~s}$ for Case 1 and $1.64 \mathrm{~s}$ for Case 2. The flame radius, which is defined in this study as the radius of peak

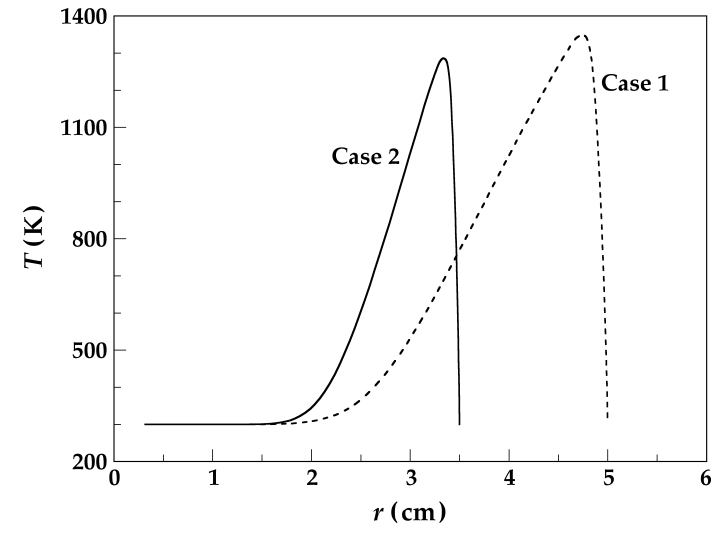

Figure 3. Modeled radial temperature profiles for two initial conditions for a flame of oxygen flowing into $4 \%$ ethylene at $104 \mathrm{mg} / \mathrm{s}$. The two cases are steady-state solutions without radiation and with outer boundaries at and $5 \mathrm{~cm}$ (Case 1) and $3.5 \mathrm{~cm}$ (Case 2) from the center of the burner. 
temperature, increases until extinction, at which time it shrinks. The two different initial conditions of Fig. 3 lead to nearly identical extinction flame temperatures. They result in a shorter extinction time for the larger initial flame (Case 1). The large flowrate of $104 \mathrm{mg} / \mathrm{s}$ was selected in this demonstration to clearly illustrate the differences.

The basic trends of these results are similar to those of Tse et al. [28] in that radiative losses appear to dominate the flame, leading to a continuous reduction in flame temperature and, given enough time, flame extinction. The initial temperature rise $(\mathrm{t}<0.1 \mathrm{~s})$ occurs because in the compressed solution, although there is no radiative heat loss, there is significant heat loss to the "outer wall" (as seen in Fig. 3). This yields a peak temperature for the compressed solution (initial condition) that is less than the early peak temperature of the actual flame (which does not suffer from wall loss). Thus, upon ignition there is an immediate and momentary rise in flame temperature until radiative losses increase and the temperature begins to decrease. As seen in Fig. 4, Case 1 has a lower maximum temperature and extinguishes earlier than Case 2 because the compressed flame is larger (see Fig. 3) and thus after ignition the flame suffers more radiative loss. The mass flow rate of these flames is sufficiently high that there is no conductive loss to the burner as evidenced by a negligible temperature gradient near the burner.

We use maximum flame radius to define predicted extinction because when the flame extinguishes the location of the peak temperature stops growing and the flame stops consuming reactants (recall the flame radius is defined as the location of peak temperature). After heat release ceases (i.e., after extinction), heat dissipation causes the maximum temperature and its distance from the burner to decrease. As revealed in Fig. 4, the maximum flame radius provides a more sensitive indication of extinction than the initial temperature drop.

The criterion employed for identifying appropriate initial conditions was to compress the initial condition until further compression would prevent ignition, presumably because burner heat loss was too great. Maximum compression minimizes gaseous radiation by minimizing the volume of radiating species. Following this approach, the maximum temperature after ignition was found to be similar for all flowrates, except for cases where the flame suffered from burner heat loss, as will be discussed below.

In Fig. 5 the radiative heat loss rate $\left(Q_{R}\right)$, the heat release rate $\left(Q_{C}\right)$, and $Q_{R} / Q_{C}$ are plotted versus time for Case 2 of Figs. 3 and 4 so that the events leading to extinction can be clearly delineated.

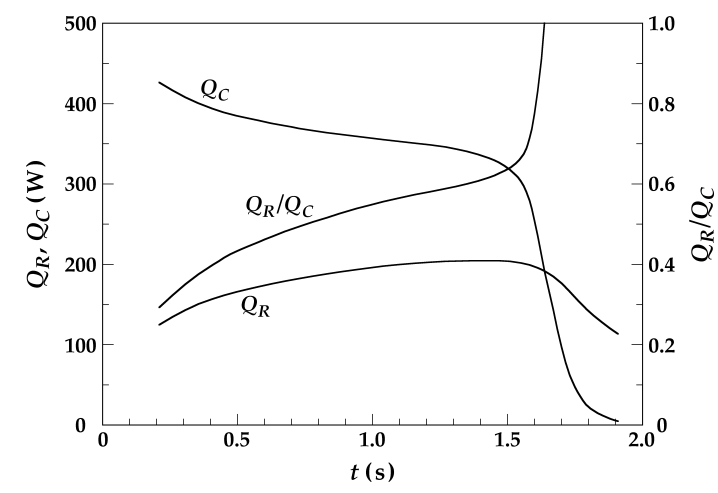

Figure 5. Modeled radiation loss rate $\left(Q_{R}\right)$, heat release rate $\left(Q_{C}\right)$ and $Q_{R} / Q_{C}$ as a function of time for Case 2 of Figs. 3 and 4. 
While the radiative heat losses increase with time, the increase is rather slow and nearly asymptotes. The heat release rate decreases slowly as well, such that extinction is a consequence of a gradual increase in radiative loss coupled with a gradual decrease in heat release. The flame extinguishes when $Q_{R} / Q_{C}$ approaches 0.7 , wherein the temperature is too low to sustain radical production (i.e., $T=T_{e x}$ ). An interesting feature of this figure is that extinction is not as much driven by a rapid rise in radiative heat loss with time (or flame size) as it is by a reduction in heat release rate with time. The reduction in heat release rate is due to the gradual reduction in temperature, which is driven by radiative losses.

Experimental and numerical results on flame extinction for oxygen flowing into $4 \%$ ethylene are shown in Fig. 6. Two extinction times are shown: base extinction and hole extinction. Both indicate the time after ignition at which extinction is first observed, starting either at the region near the supply tube (base extinction) or elsewhere (hole extinction). At later times the entire flame will extinguish but the times indicated are representative of the onset of extinction. Also shown is the radius of the flame at extinction. There is good agreement between experiment and computation for extinction flame radius for the present range of experimental flowrates. Experimental results at higher flowrates were not

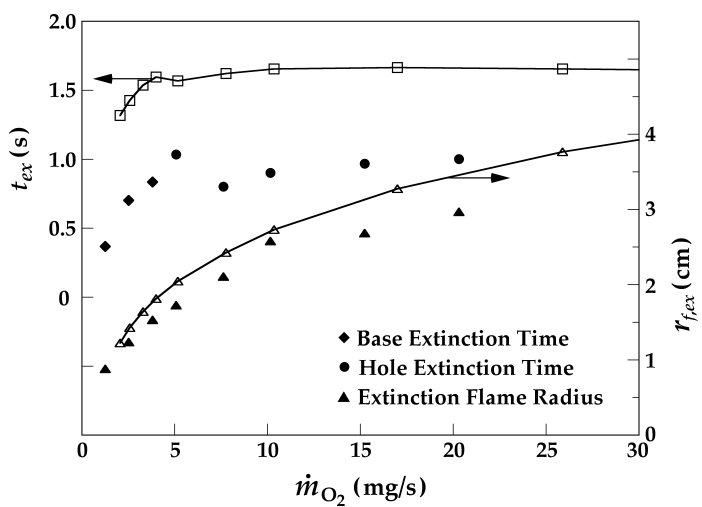

Figure 6. Measured and predicted extinction times and extinction radii for flames of oxygen flowing into $4 \%$ ethylene. No heating wire was used. Open symbols represent numerical extinction. possible due to flow nonuniformities and the onset of oblong flames. Numerical computations also show that flame size increases with flowrate and that extinction radius roughly scales with the square root of flowrate. The data in Fig. 6 reveals that the best-fit exponent on flowrate is 0.44. The trends in extinction time with flowrate are similar for experiment and computation. Initially the extinction time increases with flowrate but at about $10 \mathrm{mg} / \mathrm{s}$ it levels off, asymptoting to about $1 \mathrm{~s}$ for the experiments and $1.65 \mathrm{~s}$ numerically. The shorter extinction time at low flowrate is due to the reduction in flame temperature by burner heat loss. The closer the flame is to the burner, the greater is the heat loss to the burner. The temperature is lower and consequently less time is required to reach the extinction temperature. Although burner heat loss affects the time to extinction, the trigger for extinction is still radiative heat loss, not burner heat loss (or what might be call kinetic extinction). In other words, for the lower flowrate cases, the enthalpy that is removed from the gas mixture due to burner heat loss causes radiative extinction to occur at shorter times.

The extinction temperature is nearly invariant with flow rate (Fig. 7), even with those flames that suffer from burner heat loss. For the oxygen into $4 \%$ ethylene flames the extinction temperature was $1100 \mathrm{~K}$ at the lowest flow rates

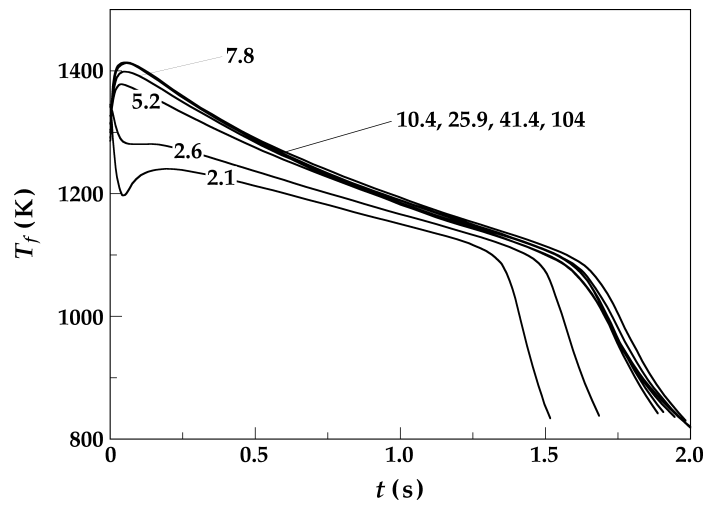

Figure 7. Modeled flame temperatures for different flowrates of flames of oxygen flowing into $4 \%$ ethylene. The curve labels represent oxygen flowrates in $\mathrm{mg} / \mathrm{s}$. 
and it dropped less than $50 \mathrm{~K}$ to $1055 \mathrm{~K}$ at $104 \mathrm{mg} / \mathrm{s}$. This result is expected, as the chemistry of extinction would not be expected to be a function of flowrate when the mechanism for extinction is radiation because this global heat loss mechanism will suppress the flame temperature uniformly throughout the flame.

At high flowrates the results of Fig. 7 are similar to Fig. 4, where the temperature first increases slightly and then continuously falls off until extinction at about $1.65 \mathrm{~s}$. Extinction is seen here as a rapid drop in peak temperature, indicating the end of heat generation. For flowrates less than 3 $\mathrm{mg} / \mathrm{s}$, a different trend is observed at early times. Here the temperature initially decreases and then increases before it begins its slow decrease to extinction due to radiative heat loss. These conditions indicate burner heat loss for the lower flowrates and it is evident that the decrease in temperature at early times results in a lower initial temperature and thus a shorter time for extinction. However, for flowrates greater than about $8 \mathrm{mg} / \mathrm{s}$ the temperature versus time curves are practically identical.

Thin-filament pyrometry measurements, shown in Fig. 8, are consistent with the numerical results in that for flows greater than $5 \mathrm{mg} / \mathrm{s}$ the temperatures (i.e., filament intensities) are nearly identical and for lower flowrates the temperature decreases with decreasing flowrate. These results were taken at a slightly higher ethylene concentration $(5 \%$ as opposed to $4 \%$ ) to ensure that the flames did not extinguish prematurely due to the presence of the filaments.

The present results indicate an extinction temperature of about $1100 \mathrm{~K}$ for the present flames (Figs. 4 and 7). This is lower than past measurements of this property in normal-gravity

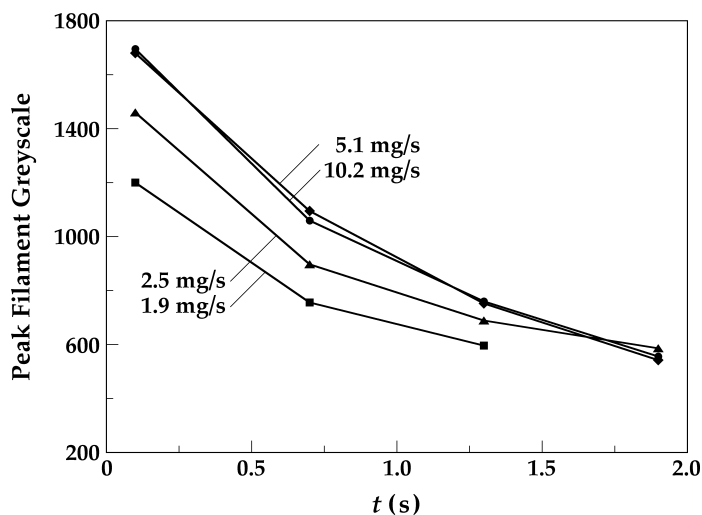

Figure 8. Thin-filament pyrometry average peak greyscales for flames of oxygen flowing into $5 \%$ ethylene. These are non-extinguishing flames except at 1.9 and $2.5 \mathrm{mg} / \mathrm{s}$. flames [29]. For example, Williams [30] indicates an extinction temperature of $1500 \pm 50 \mathrm{~K}$ for hydrocarbon combustion in oxygen/nitrogen mixtures. Macek [31] reports an extinction temperature of $1600 \mathrm{~K}$ for both diffusion and premixed flames. The significantly lower temperature at extinction reported here for microgravity diffusion flames is consistent with radiative extinction, as predicted by the analytical study of Chao et al. [4].

Results for extinction time and extinction radius as a function of flowrate for propane flowing into $17 \%$ oxygen are shown in Fig. 9. Again, there is good agreement between experiment and computation for the extinction radius. Nonetheless, the numerical results for extinction time at low flowrates show a trend that does not agree with experiments or the results in Fig. 6. Moreover, the best-fit exponent of flame radius on flowrate is 0.36 . In Fig. 9, except for a narrow range of low flowrates, the extinction time monotonically decreases and asymptotes to 2 s.

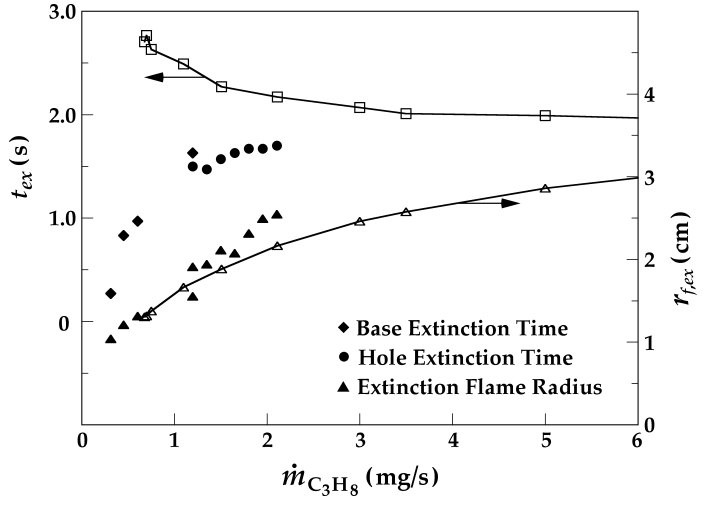

Figure 9. Measured and predicted extinction times and extinction radii for flames of propane flowing into $17 \%$ oxygen. A heating wire was used. 
This result may appear inconsistent with the discussion of Fig. 6 and further study will be necessary to explain this result - but here we will consider the consistent trend for the two cases, that of the asymptotic behavior at large flowrates, indicating that extinction time is independent of flowrate.

As shown in Figs. 6 and 9, the flame size at extinction increases with flowrate and thus it might be expected that larger flames would extinguish earlier because radiative losses would be greater in the larger flames. Indeed, steady-state theories of extinction $[4,12,13]$ indicate that increasing flame size leads to extinction due to the greater radiative losses with flame size. However, as shown in Fig. 10, for these transient flames this is not the case. Here the radiative heat loss rate $\left(Q_{R}\right)$, the heat release rate $\left(Q_{C}\right)$, and $Q_{R} / Q_{C}$ are plotted versus oxygen flowrate just before extinction. Clearly as flowrate and flame radius increase, radiative heat losses increase. But at the same time, the heat release rate increases because the flame surface area (fuel consumption rate) increases. The plot of $Q_{R} / Q_{C}$ indicates that this ratio, which is the primary variable affecting flame extinction, initially increases rapidly with flowrate but then slows dramatically for flowrates above $10 \mathrm{mg} / \mathrm{s}$. This explains why at high flowrates all flames have similar temperature versus time relationships (Fig. 7) even though the flame sizes are different. These flames do not experience burner heat loss and since the ratio of radiative heat loss to heat release is similar for these flames, they experience the same flame temperature history.

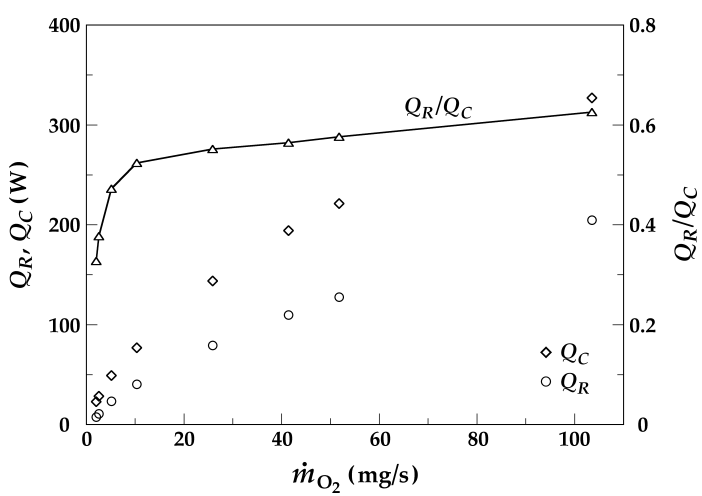

Figure 10. Modeled radiation loss rate $\left(Q_{R}\right)$, heat release rate $\left(Q_{C}\right)$ and $Q_{R} / Q_{C}$ near extinction for different flowrates plotted versus flowrate. Results shown are for flames of oxygen flowing into $4 \%$ $\mathrm{C}_{2} \mathrm{H}_{4}$.

While heat release rate increases with flowrate, the ratio of $Q_{R} / Q_{C}$ shown in Fig. 10 is nearly constant, which suggests that for large flames radiative heat losses scale with surface area, not volume. To understand this, we have plotted in Fig. 11 the mole fraction of $\mathrm{CO}_{2}$ for the flames of Fig. 6 at $0.5 \mathrm{~s}$ after ignition. Both $\mathrm{CO}_{2}$ and water are responsible for radiative heat loss but we will concentrate on $\mathrm{CO}_{2}$ with the understanding that the key findings will be similar for water vapor. The data are plotted relative to the flame location, i.e., $r-r_{f}$, where $r$ is the radius and $r_{f}$ is the flame location. While the thickness of the $\mathrm{CO}_{2}$ layer increases with flowrate on the inside of the flame, it is clear that the thickness outside the flame is nearly constant and it is this region that dominates the radiative loss from the flame. We can understand this as follows: first, the volume of each layer scales with radius squared and since the flame exterior has a larger radius than the flame interior, its volume will be considerably greater. Second, since these flames are optically thick, some of the radiation from the inside layer will be trapped by the outside layer and thus will not constitute a "loss."

The invariance in the outer layer thickness for a wide range of flowrates implies that the volume of the radiative zone increases with surface area. This explains why the ratio of $Q_{R} / Q_{C}$ starts to level off in Fig. 10 because when heat loss to the burner is negligible, both $Q_{R}$ and $Q_{C}$ scale with flame surface area. With this explanation, it is also clear why radiative losses grow only slowly with time (as seen in Fig. 5). 


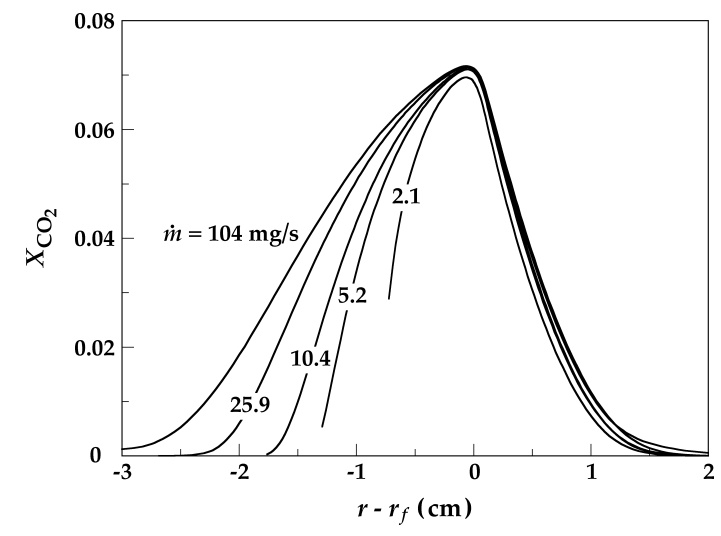

Figure 11. Modeled mole fraction of $\mathrm{CO}_{2}$ as a function of radius. In these flames oxygen flowed into $4 \%$ ethylene in nitrogen at various flowrates. Oxygen flowrates (in $\mathrm{mg} / \mathrm{s}$ ) are labeled for each curve. The curves correspond to times of $0.5 \mathrm{~s}$ after ignition. Symbols $r$ and $r_{f}$ indicate radius and radius at peak temperature, respectively.

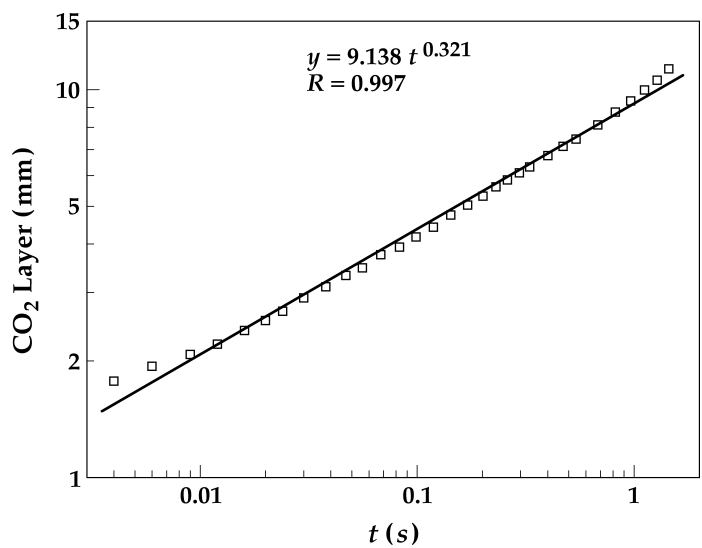

Figure 12. Thickness of the $\mathrm{CO}_{2}$ layer as a function of time. Thickness is defined as the region where the mole fraction of $\mathrm{CO}_{2}$ drops to $35 \%$ of its peak value in the outer layer of the flame. The data shown are for a flame of oxygen issuing into $4 \%$ ethylene at $41 \mathrm{mg} / \mathrm{s}$.

In the outer layer the spread rate of the radiating species $\left(\mathrm{CO}_{2}\right.$ and $\left.\mathrm{H}_{2} \mathrm{O}\right)$ is due to diffusion, not mass flowrate, and since there is an infinite domain, there is no characteristic length associated with the spread. Then, from simple scaling laws we see that the diffusion thickness $\delta$ scales with $(D t)^{1 / 2}$, where $D$ is diffusivity and $t$ is time. Approximating $D$ as $1 \mathrm{~cm}^{2} / \mathrm{s}$ and $t$ as $0.5 \mathrm{~s}$ yields a diffusion thickness on the order of $0.7 \mathrm{~cm}$, which is consistent with the thickness of the outer layer shown in Fig. 11. Figure 12 shows how the thickness of the $\mathrm{CO}_{2}$ layer in the outer layer varies with time. The power law fit shows the exponent on time is 0.32 , which is slightly smaller than the estimated value of 0.5 . This is likely due to the temperature dependence of $D$.

Fig. 13 shows that $\mathrm{CO}_{2}$ mole fraction profiles are similar in normal, low- $Z_{s t} \mathrm{C}_{3} \mathrm{H}_{8}$ flames. These predictions, along with those of Fig. 11, which are for an inverse high- $Z_{s t} \mathrm{C}_{2} \mathrm{H}_{4}$ flame, indicate that these profiles are independent of fuel type and normal versus inverse configurations. This helps explain why these flames have similar extinction times as shown in Figs. 6 and 9 and is consistent with the diffusion thickness argument above, wherein the diffusion time dominates the extinction, and fuel type and flame configuration are of secondary importance.

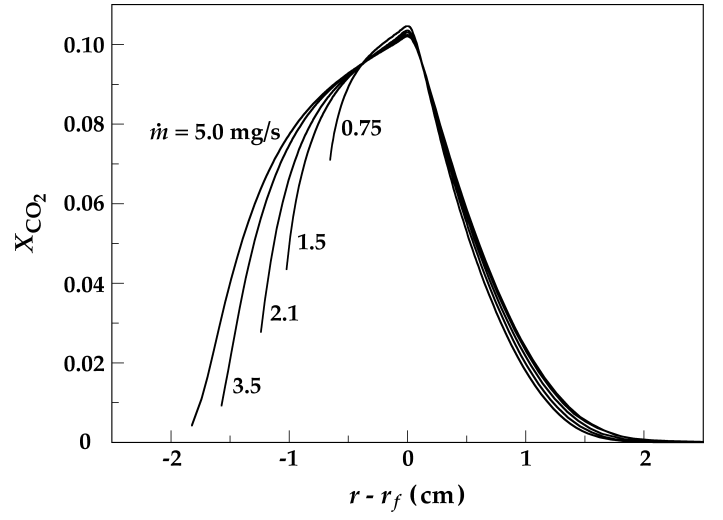

Figure 13. Comparison of modeled $\mathrm{CO}_{2}$ mole fractions for flames of $\mathrm{C}_{3} \mathrm{H}_{8}$ flowing into $17 \% \mathrm{O}_{2}$. Flowrates (in $\mathrm{mg} / \mathrm{s}$ ) are labeled for each curve. The curves correspond to times of $0.5 \mathrm{~s}$ after ignition. 


\section{Conclusions}

Spherical burner-supported diffusion flames were observed and modeled to examine radiative and kinetic extinction during transient burning. The major findings are:

1. Flames were observed that ignited and extinguished within the $2.2 \mathrm{~s}$ available test time. Two modes of extinction were identified: base and hole extinction. The onset times of both modes were the same within experimental uncertainties. Predictions indicate that peak temperatures at extinction onset were about $1100 \mathrm{~K}$.

2. The experiments and computations indicate that spherical diffusion flames generally grow and cool from ignition to extinction. Except at low flowrates, the peak temperature decreases monotonically with time, but is independent of flowrate.

3. Extinction radius roughly scales with flowrate raised to the 0.4 power.

4. At low flowrates extinction time increases with flowrate owing to burner heating effects. At high flowrates extinction time is relatively independent of flowrate.

5. Radiative heat loss is dominated by the region outside of the flame and thus scales with flame surface area, not flame volume. For large transient flames, heat release rate also scales with surface area such that radiative loss fraction is relatively independent of flowrate.

6. While radiative heat losses can drive extinction, it is not because radiative losses are increasing with time (flame size) but rather they are remaining nearly constant and the heat release rate is falling off as the temperature drops.

\section{Acknowledgments}

This work was supported by NASA Grants NCC3-697 and NCC3-1063 (RLA), NCC3-696 and NCC3-1062 (BHC), and NNC05-AA46A (PBS) under the management of M.K. King. The authors are grateful to Mr. Jason Taylor for his assistance with the drop tower experiments, Mr. Jignesh Maun for help with the filament pyrometry and Dr. Sun Zhen for many suggestions on the numerical work.

\section{References}

[1] J. Du, R.L. Axelbaum, Proc. Combust. Inst. 26 (1996) 1137-1142.

[2] H.K. Chelliah, C.K. Law, T. Ueda, M.D. Smooke, F.A. Williams, Proc. Combust. Inst. 23 (1990) $503-511$.

[3] R. Chen, R.L. Axelbaum, Combust. Flame 142 (2005) 62-71.

[4] B.H. Chao, C.K. Law, J.S. T'ien, Proc. Combust. Inst. 23 (1990) 523-531.

[5] C.K. Law, Combust. Flame 24 (1975) 89-98.

[6] K. Mills, M. Matalon, Combust. Sci. Tech. 129 (1997) 295-319.

[7] D.L. Dietrich, J.B. Haggard, F.L. Dryer, V. Nayagam, B.D. Shaw, F.A. Williams, Proc. Combust. Inst. 26 (1996) 1201-1207.

[8] V. Nayagam, J.B. Haggard, R.O. Colantonio, A.J. Marchese, F.L. Dryer, B.L. Zhang, F.A. Williams, AIAA J. 36 (8) (1998) 1369-1378.

[9] S. Liu, B.H. Chao, R.L. Axelbaum, Combust. Fame 140 (2005) 1-23.

[10] S.W. Yoo, E.W. Christiansen, C.K. and Law, Proc. Combust. Inst. 29 (2002) 29-36.

[11] M.K. King, Proc. Combust. Inst. 26 (1996) 1227-1234.

[12] A. Atreya, S. Agrawal, Combust. Flame 115 (1998) 372-383.

[13] K. Mills, M. Matalon, Proc. Combust. Inst. 27 (1998) 2535-2541.

[14] E.W. Christiansen, S.D. Tse, C.K. Law, Combust. Flame 134 (2003) 327-337. 
[15] K. Maruta, M. Yoshida, H. Guo, Y. Ju, T. Niioka, Combust. Flame 112 (1998) 181-187.

[16] P.B. Sunderland, R.L. Axelbaum, D.L. Urban, B.H. Chao, S. Liu, Combust. Flame 132 (2003) 25-33.

[17] P.B. Sunderland, D.L. Urban, D.P. Stocker, B.H. Chao, R.L. Axelbaum, Combust. Sci. Tech. 176 (2004) 21432164.

[18] V. Villimpoc, L.P. Goss, Proc. Combust. Inst. 22 (1988) 1907-1914.

[19] B.C. Connelly, S.A. Kaiser, M.D. Smooke, M.B. Long, Fourth Joint Meeting of the U.S. Sections of the Combustion Institute, Philadelphia, 2005.

[20] J.D. Maun, P.B. Sunderland, D.L. Urban, Applied Optics, accepted.

[21] R.J. Kee, J.F. Grcar, M.D. Smooke, J.A. Miller, E. Meeks, A Program for Modeling Steady, Laminar, OneDimensional Premixed Flames, Report No. SAND85-8240, Sandia National Laboratories, 1987.

[22] L.S. Rothman, C.P. Rinsland, A. Goldman, S.T. Massie, D.P. Edwards, J.-M. Flaud, A. Perrin, C. Camy-Peyret, V. Dana, J.-Y. Mandin, J. Schroeder, A. Mccann, R.R. Gamache, R.B. Wattson, K. Yoshino, K.V. Chance, K.W. Jucks, L.R. Brown, V. Nemtchinov, P. Varanasi, J. Quant. Spectrosc. Radiat. Transf. 82 (2003) 5-44.

[23] B.G. Carlson, K.D. Lathrop, in H. Greenspan, C.N. Kelber, D. Okrent (Eds.), Computing Methods in Reactor Physics, Gordon and Breach, New York, 1968, pp. 171-266.

[24] J.F. Grcar, The Twopnt Program for Boundary Value Problems, Report SAND91-8230, Sandia National Laboratories, 1992.

[25] R.J. Kee, F.M. Rupley, J.A. Miller, Chemkin-II: A Fortran Chemical Kinetics Package for the Analysis of Gas Phase Chemical Kinetics, Report SAND89-8009B, Sandia National Laboratories, 1989.

[26] R.J. Kee, G. Dixon-Lewis, J. Warnatz, M.E. Coltrin, J.A. Miller, A Fortran Computer Code Package for the Evaluation of Gas Phase Multicomponent Transport Properties, Report SAND86-8246, Sandia National Laboratories, 1988.

[27] G.P. Smith, D.M. Golden, M. Frenklach, N.W. Moriarty, B. Eiteneer, M. Goldenberg, C.T. Bowman, R.K. Hanson, S. Song, W.C. Gardiner Jr., V.V. Lissianski, Z. Qin, available at http://www.me.berkeley.edu/gri_mech/.

[28] S.D. Tse, D. Zhu, C.-J. Sung, Y. Ju, C.K. Law, Combust. Flame 125 (2001) 1265-1278.

[29] J.G. Quintiere, Fundamentals of Fire Phenomena, Wiley, p. 277 (2006).

[30] F.A. Williams, Fire Safety J. 3 (1981) 163-175.

[31] A. Macek, Flammability Limits: Thermodynamics and Kinetics, NBSIR Report 76-1076, National Bureau of Standards, Gaithersburg, Maryland (1976). 